\title{
COMPARISON OF TWO HEPARIN-COATED EXTRACORPOREAL CIRCUITS WITH REDUCED SYSTEMIC ANTICOAGULATION IN ROUTINE CORONARY ARTERY BYPASS OPERATIONS
}

\author{
Eivind Øvrum, MD, $\mathrm{PhD}$ \\ Geir Tangen, MD \\ Rolf Øystese, CCP \\ Mari Anne L. Ringdal, CCP \\ Reidar Istad, CCP \\ For related editorial, see p. 200.
}

Objectives: The use of heparin-coated circuits for cardiopulmonary bypass attenuates the postperfusion inflammatory response. Postoperative bleeding and the need for allogeneic blood transfusions are reduced, particularly in combination with lowered systemic anticoagulation. The two most commonly used heparin-coated systems are the Carmeda BioActive Surface (Medtronic Inc, Minneapolis, Minn) and the Duraflo II coating (Baxter Healthcare Corp, Bentley Laboratories Division, Irvine, Calif). The 2 surfaces are technically unequal, and previous experimental studies have demonstrated disparities in effects on the immune system and the blood cells. However, no larger comparative studies of relevant clinical end points have thus far been reported.

Methods: Over a 24-month period, all patients undergoing coronary artery bypass were prospectively randomized to one of the two heparin-coated circuits. Altogether, 1336 consecutive patients were included. The heparin dose was reduced in all cases, with an activated coagulation time of more than 250 seconds. Clinical data were consecutively collected and stored on a computer for comparative analyses.

Results: There were no statistically significant differences in any demographic or operative parameters. The Duraflo II patients required less heparin to keep the target-activated clotting time, confirming the previous finding of some leakage of heparin from the surface to the circulation. Otherwise, there were no significant differences in time for ventilatory support (Duraflo II, $1.7 \pm 1.3$ hours; Carmeda BioActive Surface, $1.6 \pm 1.0$ hours; $P=.37$ ), amount of postoperative mediastinal drainage (Duraflo II, $665 \pm 257 \mathrm{~mL}$; Carmeda BioActive Surface, $688 \pm 243 \mathrm{~mL} ; P=.07$ ), need for allogeneic blood-plasma transfusions (Duraflo II, $4.2 \%$ of the patients; Carmeda BioActive Surface, $4.4 \%$ of the patients; $P=.93$ ), or hemoglobin concentration at hospital discharge (Duraflo II, $120 \pm 13 \mathrm{~g} / \mathrm{L}$; Carmeda BioActive Surface, $119 \pm 13 \mathrm{~g} / \mathrm{L} ; P=.08)$. The effects on renal function and platelets were similar, as were the incidences of perioperative myocardial infarction (Duraflo II, 1.5\%; Carmeda BioActive Surface, 1.5\%; $P=.96$ ), stroke (Duraflo II, 1.3\%; Carmeda BioActive Surface, $1.2 \% ; P=.47$ ), and hospital mortality (Duraflo II, 1 [0.14\%] patient; Carmeda BioActive Surface, $3[0.45 \%]$ patients; $P=.31)$.

Conclusions: Despite differences in technology, complexity, and effects on biologic markers, no clinical differences were observed between the Carmeda BioActive Surface system and the Duraflo II coating after coronary artery bypass operations. The overall clinical results were favorable in both groups, confirming the safety and feasibility of routine use of heparin-coated circuits in combination with reduced systemic anticoagulation.

(J Thorac Cardiovasc Surg 2001;121:324-30)
From the Oslo Heart Center, Oslo, Norway.

Received for publication April 6, 2000; revisions requested June 19, 2000; revisions received Aug 14, 2000; accepted for publication Aug 31, 2000.

Address for reprints: Eivind $\emptyset v r u m, \mathrm{MD}, \mathrm{PhD}$, Oslo Heart Center,
Box 2684 St, Hanshaugen, 0131 Oslo, Norway.

Copyright (C) 2001 by The American Association for Thoracic Surgery

0022-5223/2001 $\$ 35.00+0 \quad \mathbf{1 2 / 1 / 1 1 1 2 0 5}$

doi:10.1067/mtc.2001.111205 
mplementation of heparin-coated cardiopulmonary bypass (CPB) circuits in cardiac operations has proved to attenuate the activation of biologic cascades ${ }^{1-4}$ and is assumed to reduce the risk of postperfusion injury. 5,6 The presence of thromboresistant heparinized surfaces has further allowed lower doses of systemic heparin, with a subsequent reduced need for protamine. This option has been shown to decrease postoperative bleeding and requirements for bank blood transfusions and has led to reduced postoperative morbidity. ${ }^{7-10}$

Among a variety of biologically modified surfaces, ${ }^{11} 2$ separate processes for coating of extracorporeal circuits with immobilized heparin have been available for routine clinical use for many years. The Carmeda BioActive Surface (CBAS) (Medtronic Inc, Minneapolis, Minn) involves deposition of a polymer coating, polyethylenimine, onto various types of surfaces. Heparin fragments, prepared from the degradation of heparin in nitrous acid, are then end point attached and covalently bonded to the polymer. ${ }^{12}$ The Duraflo II (Baxter Healthcare Corp, Bentley Laboratories Division, Irvine, Calif) process is based on the concept of modifying the physiochemical properties of unfractionated heparin with a proprietary binding agent that has high affinity to a variety of synthetic surfaces. ${ }^{13}$ In general, the CBAS appears more complex, but also more stable, than the Duraflo II coating. ${ }^{14}$ Reduced complement and granulocyte activation has been demonstrated individually for both systems, and in some comparative studies, these effects were more pronounced for the CBAS than for the Duraflo II surface. ${ }^{14,15}$ Also, the release of endothelin 1 was more reduced with the CBAS equipment than with the Duraflo II. ${ }^{16}$ However, no studies of larger patient series have been reported, evaluating possible differences in clinical outcome variables with the 2 heparinized systems.

The purpose of this study was to accumulate information in a prospectively randomized fashion, focusing on the most relevant perioperative and postoperative variables in patients undergoing coronary artery bypass operations.

\section{Patients and methods}

Patients. From January 1998 through December 1999, 1336 consecutive patients underwent myocardial revascularization with the heart-lung machine in our department. All patients admitted for coronary bypass operations, regardless of operative risk profile, were included in the study. Because the use of heparin-coated circuits with reduced anticoagulation is routine in our institution, no informed consent was obtained from the patients. The majority of the patients underwent their operations on an elective basis $(9.1 \%$ were emergency cases), and $30(2.2 \%)$ patients had their second revascularization. No patients were receiving mechanical pump support preoperatively. The patient material is somewhat selected because of the close collaboration with a neighboring university department, in which patients with severe renal dysfunction, patients with ventricular aneurysms, patients in need of a combined carotid and coronary operation, and patients undergoing acute operations after failed angioplasties are cared for. Otherwise, a typical coronary artery bypass patient population was treated (Table I).

Randomization and operation. Two identical operating rooms (ORs) were available, and one of the two heparin-coated CPB systems was used in each room. All patients were randomly allocated to one of the ORs, as were the surgeons, anesthetists, perfusionists, and nurses. More than $75 \%$ of the patients were operated on by one of two surgeons (E.Ø., G.T.). The setups of CPB equipment were switched from one OR to the other every 6 months to avoid any possible selection bias.

The anesthesia protocol was designed to permit early postoperative extubation and included mainly a combination of diazepam $(0-0.2 \mathrm{mg} / \mathrm{kg})$, midazolam hydrochloride $(0-0.2$ $\mathrm{mg} / \mathrm{kg}$ ), fentanyl (4-8 $\mu \mathrm{g} / \mathrm{kg}$ ), and pancuronium bromide supplemented with isoflurane and nitrous oxide.

At least one internal thoracic artery anastomosis was constructed in all but 9 patients (99.3\%), supplemented with saphenous vein grafts. The aorta was crossclamped during performance of the distal anastomoses. Myocardial protection consisted of intermittent antegrade administration of cold blood cardioplegic solution or crystalloid cardioplegic solution (St Thomas' Hospital solution No. 2). Blood cardioplegia was restricted to high-risk patients, who were defined as having the following characteristics: (1) age greater than 70 years; (2) insulin-dependent diabetes; (3) unstable angina; (4) left ventricular ejection fraction of less than 0.5 ; and (5) emergency operation.

The proximal anastomoses were performed during partial occlusion of the ascending aorta while the patient was being rewarmed. The blood conservation protocol of the institution, previously described in detail, ${ }^{17}$ was applied to all patients. The protocol includes autologous blood removal before $\mathrm{CPB}$ with later retransfusion, returning of all contents of the extracorporeal circuit to the patient, and autotransfusion of the shed mediastinal blood until 18 hours after the operation. Antifibrinolytic therapy or anti-inflammatory drugs were not given to any patients. The amount of postoperative bleeding from the time of sternal closure until the drains were removed was recorded. Normovolemic anemia was accepted to a hematocrit level of 0.25 postoperatively; a level below this was considered an indication for allogeneic red blood cell transfusion. The hemoglobin concentration, as well as platelet counts, were determined preoperatively, at 3 and 18 hours postoperatively, and at discharge on the fifth to seventh day. Kidney function was monitored by repeated measurements of the serum creatinine level before and after the operation.

CPB and anticoagulation. Every part of the circuit was coated with heparin (tip-to-tip), including cannulas, switches, and connectors. The two CPB systems under investigation had the following characteristics: 
Table I. Demographic data and operative details of the Duraflo II group and the CBAS group

\begin{tabular}{lccc}
\hline Clinical parameters & Duraflo II group $(n=675)$ & CBAS group $(n=661)$ & P value \\
\hline Age (y) & $63.9 \pm 9.5$ & $64.0 \pm 9.6$ & .78 \\
Female sex (\%) & 20.9 & 18.0 & .21 \\
Weight (kg) & $80.6 \pm 17.0$ & $81.9 \pm 17.3$ & .08 \\
Emergency operation (\% of patients) & 9.0 & 9.1 & .76 \\
Redo operation (\% of patients) & 1.8 & 2.7 & .24 \\
Ejection fraction & $0.67 \pm 0.14$ & $0.67 \pm 0.14$ & .86 \\
Left main stenosis (\% of patients) & 25.2 & 25.9 & .76 \\
Previous myocardial infarction (\%) & 51.4 & 48.4 & .27 \\
Blood cardioplegia (high-risk patients; \%) & 36.3 & 38.9 & .35 \\
No. of distal anastomoses & $4.6 \pm 1.3$ & $4.6 \pm 1.3$ & .67 \\
Ischemic time (min) & $34.9 \pm 10.4$ & $35.6 \pm 10.9$ & .35 \\
Extracorporeal time (min) & $56.6 \pm 15.4$ & $57.0 \pm 15.4$ & .36 \\
Spontaneous sinus rhythm after declamping (\%) & 88.6 & 85.3 & .07
\end{tabular}

Values are given as mean \pm SD where shown. There were no statistically significant differences between the groups.

Table II. Heparin and protamine sulfate doses given to the Duraflo II group and the CBAS group

\begin{tabular}{lccr}
\hline & Duraflo II group $(n=675)$ & CBAS group $(n=661)$ & P value \\
\hline Pre-CPB heparin (IU) & $9,507 \pm 2,245$ & $10,182 \pm 2,628$ & $<.0001$ \\
Supplemental heparin during CPB (IU) & $732 \pm 1517$ & $3,174 \pm 2,545$ & $<.0001$ \\
Protamine sulphate after CPB (mg) & $128.3 \pm 28.5$ & $136.9 \pm 34.1$ & $<.0001$ \\
Supplemental protamine sulphate in ICU (mg) & $29.8 \pm 16.7(\mathrm{n}=109)$ & $29.3 \pm 9.8(\mathrm{n}=91)$ & .51 \\
\hline
\end{tabular}

Values are given as mean $\pm \mathrm{SD}$ where shown. ICU, Intensive care unit.

1. In the Duraflo II circuit, all surfaces in contact with blood were coated with a water-insoluble heparin complex. The circuit consisted of silicone and polyvinyl chloride tubings connected to a hard-shell cardiotomy reservoir (DII BCR-3500 Gold); a softshell venous reservoir (DII BMR-1900 Gold); a woven, hollow, polypropylene fiber membrane oxygenator (Spiral Gold; surface area, $1.90 \mathrm{~m}^{2}$ ); and a 25$\mu \mathrm{m}$ arterial filter (DII AF-1025 Gold).

2. In the CBAS circuit every part of the extracorporeal equipment was coated with end-attached covalentbonded heparin. The circuit included polyvinylchloride tubings connected to a hard-shell cardiotomy reservoir (CB 1351); a collapsible venous reservoir bag (CB MVR 1600); a woven, hollow, polypropylene fiber membrane oxygenator (CBMAXPRF; surface area, $2.30 \mathrm{~m}^{2}$ ); and a $20-\mu \mathrm{m}$ arterial filter (CB M-20).

The extracorporeal circulation was performed with the use of a Stöckert roller pump with a pulsatile flow control (PFC III; Stöckert Instrumente GmbH, Munich, Germany). In both groups the sizes of the aortic and the 2-stage venous cannulas were $22 \mathrm{~F}$ and $48 \mathrm{~F}$, respectively. A cardiotomy suction line was available for both systems and was frequently used during CPB. The circuits were primed with Ringer's acetate, approximately $2000 \mathrm{~mL}$ for the Duraflo II circuit and 2300 $\mathrm{mL}$ for the CBAS equipment. Mild hypothermia (blood temperature, $32^{\circ} \mathrm{C}$ ) was instituted immediately after the start of bypass. Each circuit was examined visually for evidence of clots or fibrin formation after termination of CPB.

A reduced dose of heparin (Nyco Pharma, Asker, Norway),
$100 \mathrm{IU} / \mathrm{kg}$, was used for anticoagulation. The activated clotting time (ACT; HemoTec, Englewood, Colo) had to exceed 250 seconds before $\mathrm{CPB}$ was started, and supplemental doses were administered if necessary to maintain this target ACT. ACT was repeatedly determined during $\mathrm{CPB}$, after protamine administration, and 2 hours postoperatively. For neutralization of heparin, a bolus dose of protamine (protamine sulfate; Novo Nordisk, Bagsvard, Denmark), $1.3 \mathrm{mg} / 100 \mathrm{IU}$ heparin, was given. The extracorporeal bypass was disconnected before the administration of protamine sulfate. An additional protamine dose was considered if postoperative bleeding was more than 1.5 to $2 \mathrm{~mL} / \mathrm{kg}$ body weight during the first 2 postoperative hours, if ACT was more than 140 seconds, or both.

Postoperative arrhythmias. After continuous registration of the electrocardiogram during the day of the operation, all patients were monitored with continuous telemetry for 48 hours. In cases of arrhythmias, telemetry was prolonged or reinstituted. All patients having one or more episodes of arrhythmias were prospectively registered. Preoperative medication ( $\beta$-blockers, $\mathrm{Ca}^{++}$-channel blockers, and digitalis) was continued from the first day after the operation. In those patients not receiving $\beta$-blockers preoperatively, such treatment was instituted at the first postoperative day.

Statistical analysis. Comparison of the 2 groups was done by the Mann-Whitney $U$ test for continuous variables. Discrete variables were treated by means of contingency tables with the Yates correction, and the Fisher test was performed when one of the expected cell values was less than 5 . The data are presented as means \pm SD. All data were recorded prospectively and stored in a database. 


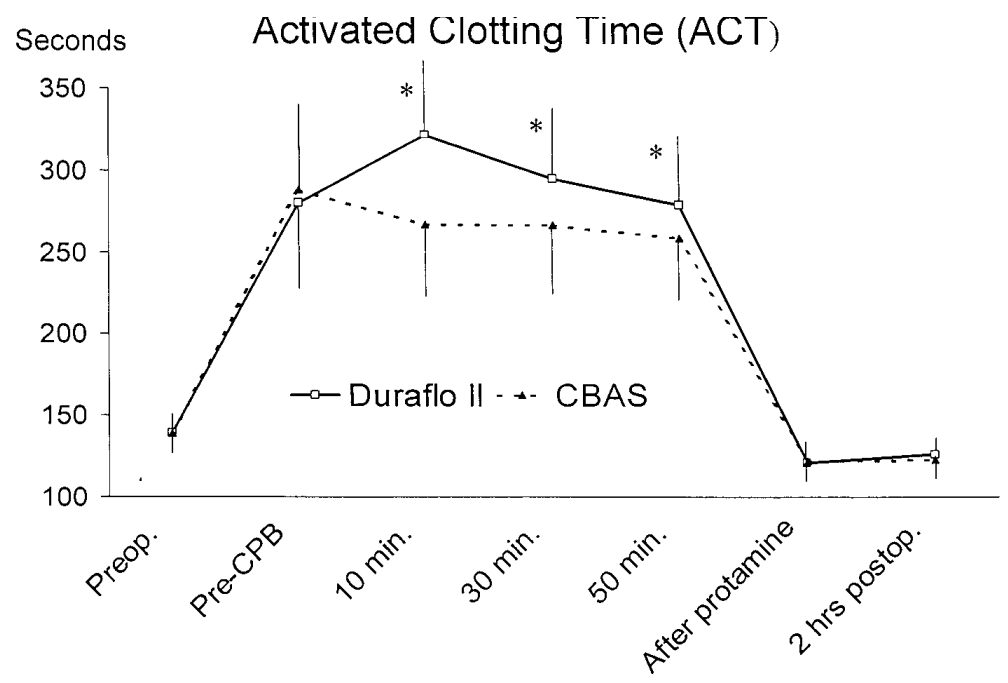

Fig 1. Despite lower doses of heparin given to the Duraflo II group, the ACT on CPB was significantly higher than that found in the CBAS group $(* P<.001)$. This is probably due to leakage of heparin from the Duraflo II surface to the circulation. Values are given as means \pm SD.

Table III. Clinical end points in the Duraflo II and CBAS groups

\begin{tabular}{lccc}
\hline Clinical end points & Duraflo II group $(n=675)$ & CBAS group $(n=661)$ & P value \\
\hline Fluid excess at ICU arrival $(\mathrm{mL})$ & $3145 \pm 777$ & $3420 \pm 882$ & .001 \\
Fluid excess during first $18 \mathrm{~h}$ postop $(\mathrm{mL})$ & $2203 \pm 860$ & $2387 \pm 899$ & .26 \\
Serum creatinine-maximal postop increase $(\mu \mathrm{mol} / \mathrm{L})$ & $7.5 \pm 30.3$ & $5.4 \pm 16.4$ & .06 \\
Ventilatory support postop (h) & $1.7 \pm 1.3$ & $1.6 \pm 1.0$ & .37 \\
Postoperative AF (preoperative AF excluded; \% of patients) & 26.4 & 27.9 & .54 \\
Perioperative myocardial infarction $(\%$ of patients) & 1.5 & 1.5 & .96 \\
Walking stairs outdoors before postop day 5 (\% of patients) & 93.0 & 92.1 & .15 \\
Stroke (\% of patients) & 1.3 & 1.2 & .47 \\
Minor neurologic events (\% of patients) & 0.6 & 0.5 & .26 \\
Mediastinitis (\% of patients) & 0.4 & 0.8 & .35 \\
Hospital mortality (\% of patients) & 0.14 & 0.45 & .31 \\
\hline
\end{tabular}

Values are given as mean $\pm \mathrm{SD}$ where shown. $I C U$, Intensive care unit; postop, postoperative; $A F$, atrial fibrillation.

\section{Results}

The demographic data are listed in Table I. The slight difference in number of patients in the 2 groups was due to a short period of delayed supply of equipment from one manufacturer. Otherwise, no significant differences were observed for any parameters. Operative characteristics, such as the number of distal anastomoses, aortic crossclamping times, and extracorporeal times, were similar, as was the distribution of high-risk patients (given blood cardioplegia). Sinus rhythm returned spontaneously after declamping of the aorta at equal proportion in the 2 groups.

Heparin was given at lower initial amounts in the Duraflo II group because the experience of heparin leakage from this surface gradually became evident during the investigation period (Table II). Even more pronounced was the much lower rate of supplemental heparin doses $(23.3 \%$ of the patients) that were required in the Duraflo II group compared with those required in the CBAS group (75.3\% of the patients; $P<.0001)$ to maintain the lower limit of the ACT. Despite this fact, the ACTs during CPB were significantly higher in the Duraflo II group $(P<.001$, Fig 1$)$. The protamine dose was given in the amount of 1.3 $\mathrm{mg} / 100 \mathrm{IU}$ initial heparin dose and was accordingly somewhat higher in the CBAS group. There were no significant intergroup differences in the postoperative ACTs, and the amount of extra protamine given postoperatively was similar in both groups. No technical problems were recorded during CPB. In the CBAS 
Table IV. Postoperative data for the Duraflo II and CBAS groups

\begin{tabular}{lccc}
\hline Postoperative data & Duraflo II group $(n=675)$ & CBAS group $(n=661)$ & P value \\
\hline Mediastinal drainage 18 h postoperatively $(\mathrm{mL})$ & $665 \pm 257$ & $688 \pm 270$ & .07 \\
Autotransfusion of shed blood (mL) & $631 \pm 249$ & $651 \pm 243$ & .05 \\
Resternotomy for bleeding (\% of patients) & 1.6 & 2.0 & .64 \\
Red cells $( \pm$ plasma) transfusions (\% of patients) & 3.3 & 3.3 & .93 \\
Plasma transfusion $(\%$ of patients) & 0.9 & $207 \pm 55$ & .96 \\
Platelets preoperatively $\left(\times 10^{3}\right)$ & $211 \pm 53$ & $223 \pm 68$ & .20 \\
Platelets at discharge $\left(\times 10^{3}\right)$ & $227 \pm 73$ & $141 \pm 12$ & .29 \\
Hemoglobin concentration preoperatively $(\mathrm{g} / \mathrm{L})$ & $142 \pm 12$ & $119 \pm 13$ & .31 \\
Hemoglobin concentration at discharge $(\mathrm{g} / \mathrm{L})$ & $120 \pm 13$ & & .08 \\
\hline
\end{tabular}

Values are given as mean \pm SD where shown.

group some clots were seen in the cardiotomy reservoirs after the operation in 2 patients having redo operations, but no clinical consequences were recorded. The lowest ACTs during CPB in these patients were 310 seconds and 271 seconds, respectively.

The clinical outcome variables are shown in Table III. An excess of fluid at the end of the operation was significantly higher in the CBAS group in accordance with the higher priming volume required for this circuit. This difference disappeared after 18 hours. For all other variables, no statistically significant differences between the groups were demonstrated. The patients were extubated early in both groups, and the incidence of new episodes of atrial fibrillation and the rate of perioperative myocardial infarction were similar. No differences were seen regarding renal function, incidence of neurologic complications, or progress of physical rehabilitation. There was $1(0.14 \%)$ hospital death in the Duraflo II group and $3(0.45 \%)$ deaths in the CBAS group $(P=.31)$.

Because of the leakage of heparin in the Duraflo II group, this instability of the surface could potentially be of importance in cases of prolonged CPB. Therefore, a separate analysis was done for patients having a CPB time of more than 60 minutes. In the CBAS group 229 patients had a CPB time of $73.3 \pm$ 12.1 minutes, and in the Duraflo group 212 patients were perfused in $73.3 \pm 14.7$ minutes $(P=.30)$. No significant differences were seen in any of the variables outlined in Table II and Table IV, except for the similar differences in fluid balance, which was shown for the entire group.

\section{Discussion}

Several studies have demonstrated that the use of heparin-coated circuits for CPB attenuates the activation of the immunologic system, the white blood cells, and the endothelial cells. ${ }^{1,4,14-16}$ These indications of reduced postperfusion inflammatory response have been shown to be more pronounced for the CBAS than for the Duraflo II surface. ${ }^{14-16}$ Both the $\mathrm{C} 3$ activation products $\mathrm{C} 3 \mathrm{~b}$, iC $3 \mathrm{~b}$, and $\mathrm{C} 3 \mathrm{c}(\mathrm{C} 3 \mathrm{bc})$ and the terminal SC5b-9 complement complex were significantly lower during CPB with the CBAS equipment compared with CPB with the Duraflo II system. ${ }^{14}$ Similarly, the same effects were seen for the granulocyte activation enzymes lactoferrin and myeloperoxidase,,${ }^{15}$ as well as for the release of endothelin $1 .{ }^{16}$ We hypothesized that the disparity in affecting biologic markers could eventually lead to corresponding clinical consequences, particularly regarding lung and kidney function, as well as postoperative bleeding and need for blood transfusions. However, in the present study there was a striking similarity of all major clinical end points in the 2 groups. The only difference in routine clinical use was the reduced need for heparin to maintain the target ACT during CPB in the Duraflo II group. This has been demonstrated both experimentally ${ }^{13}$ and in clinical studies ${ }^{14}$ and is assumed to be due to leakage of heparin to the circulation from the Duraflo II surface. In vitro recirculation loop tests of coated arterial filters ${ }^{13}$ have shown that about $10 \%$ of the bonded heparin was circulating shortly after fluid exposure but remained stable at this level for 2 hours. This instability of the Duraflo II surface could theoretically be of importance in cases with prolonged time of extracorporeal circulation. However, we were not able to demonstrate any intergroup differences when comparing the subpopulations of patients having a CPB time of more than 60 minutes. From a practical point of view, more attention has to be kept on monitoring the ACT during CPB with the CBAS system because more supplemental heparin is likely to be given. In this context it should be emphasized that duplicate ACT measurements are necessary because of considerable variability in single determinations. ${ }^{18}$ Despite the different ACTs during the opera- 
tion, the doses of protamine administered after CPB were calculated similarly in both groups $(1.3 \mathrm{mg}$ of protamine-sulphate/100 IU of heparin given before CPB) and worked out well because the need for additional protamine doses was nearly identical for both the Duraflo II and CBAS group.

The less-thrombogenic surfaces of heparin-coated circuits have allowed a reduced dose of heparin for systemic anticoagulation during CPB. This combination has been shown to be safe and blood saving in previous randomized clinical studies. ${ }^{7-10}$ Aldea and colleagues ${ }^{8}$ were able to demonstrate less bleeding and less need for allogeneic transfusions, and this was proved in a later study ${ }^{19}$ to be an effect of a reduced anticoagulation protocol with an ACT of greater than 250 seconds. They also experienced a shorter intubation time, fewer postoperative complications, and shorter intensive care unit and hospital stays. Svenmarker and colleagues ${ }^{10}$ demonstrated signs of improved cerebral protection with CBAS-coated CPB and reduced heparin dose. These previous clinical results were clearly confirmed in the present study, which included a much larger number of patients than the studies mentioned. The intubation times were short, and the overall complication and mortality rates were favorable in both groups. The postoperative bleeding was moderate, and we were able to avoid allogeneic transfusions in more than $95 \%$ of the patients. A main surgical experience was an impression of a dry operation field shortly after administration of protamine, which made the hemostasis and the whole operation less time consuming.

The effects of reduced heparin dose on postoperative bleeding is not unexpected because heparin itself is known to induce fibrinolysis and platelet dysfunction even before CPB. ${ }^{20}$ The fear of increased thrombin formation and even intravascular thrombosis when reducing systemic heparin could not be confirmed in a previous study comparing a full heparin dose (ACT $>480$ seconds) with a low heparin dose (ACT $>250$ seconds) along with heparinized CPB circuits. ${ }^{21}$ Technical problems with obstruction of the extracorporeal circuits have thus far not been recorded. Nevertheless, having recorded some clots in the cardiotomy reservoir after $\mathrm{CPB}$ in 2 redo patients, we now use a full heparin dose in this subgroup of patients. It might be suggested that in redo patients more tissue factor is released after extended dissection of scar tissue, and this may subsequently initiate local coagulation.

An additional advantage of reducing the intravenously delivered dose of heparin is the reduced need for protamine because protamine is known to cause hemodynamic instability, hypersensitivity, and complement activation. ${ }^{22}$ In particular, heparin-coated circuits and reduced systemic levels of heparin represent an alternative option for patients known to react adversely to protamine.

Clinical studies of heparin-coated CPB circuits with full systemic heparinization have thus far not been able to demonstrate any effects on postoperative bleeding or rate of transfusions. Two multicenter studies comparing Duraflo II and uncoated controls with an ACT of greater than 480 seconds in both groups have been published. ${ }^{23,24}$ In the European study, ${ }^{23}$ enrolling 805 lowrisk coronary patients, no clinical benefits were seen considering postoperative bleeding, transfusion requirements, intubation times, or recovery for the whole population. In analyses of patient subpopulations, female patients receiving heparin-coated circuits had less transfusions and were extubated earlier than the control subjects. For the subgroup of patients having an aortic crossclamp time greater than 60 minutes, a shorter intensive care treatment was recorded. A similar pattern was demonstrated in an Italian multicenter study, ${ }^{24}$ also using full heparinization in a high-risk series of 886 patients. There were no overall differences in bleeding or transfusions. However, the use of heparin-coated equipment was associated with a shorter intensive care unit and hospital stay and with a lower number of patients with a severely impaired clinical outcome.

A separate benefit for using heparin-coated circuits is reduced incidence of postoperative atrial fibrillation. In a prospectively randomized study, we reported a reduced rate of atrial fibrillation using Duraflo II-coated circuits (and full heparin dose) compared with identical uncoated controls. ${ }^{25}$ The overall incidence of new episodes of atrial fibrillation fell from $43.1 \%$ to $21.8 \%$ and was even more pronounced in the younger patients. The rate of postoperative atrial fibrillation was somewhat higher in the present study (27\%) and was probably due to a continuous increase in the number of elderly patients year by year. In the European multicenter study, ${ }^{23}$ similar beneficial influence on postoperative supraventricular arrhythmias was seen in female patients.

The reason for the absence of any disparities in clinical end points between the two heparinized surfaces, despite having different influences on inflammatory markers, remains unclear. It might be assumed that the total effects on the biologic cascades for both systems are too small to show any significant improvement of organ function during and after CPB. The present clinical end points may also be too insensitive; however, the clinical performance and postoperative recovery is 
of ultimate interest when investigating new technologies used for treatment of patients.

In summary, no significant differences in clinical performance were seen comparing the CBAS equipment with the Duraflo II-coated system during and after coronary artery bypass operations. The CBAS technology is more complex and consequently more expensive than the Duraflo II system. This fact may be of relevance, at least when considering a routine use of heparin-coated circuits for extracorporeal circulation. On the other hand, the CBAS appears more stable than the Duraflo II surface, and this may have some effect in more critically ill patients, in whom a longer extracorporeal time is necessary.

\section{REFERENCES}

1. Videm V, Svennevig JL, Fosse E, Semb G, Østerud A, Mollnes TE. Reduced complement activation with heparin-coated oxygenator and tubings in coronary bypass operations. J Thorac Cardiovasc Surg 1992;103:806-13.

2. Gu YJ, van Oeveren W, Akkerman C, Boonstra PW, Huyzen RJ, Wildevuur CRH. Heparin-coated circuits reduce the inflammatory response to cardiopulmonary bypass. Ann Thorac Surg 1993;55:917-22.

3. Fosse E, Moen O, Johnson E, Semb G, Brockmeier V, Mollnes TE, et al. Reduced complement and granulocyte activation with heparin coated cardiopulmonary bypass. Ann Thorac Surg 1994;58:472-7.

4. Pekna M, Hagman L, Haldèn E, Nilsson UR, Nilsson B, Thelin S. Complement activation during cardiopulmonary bypass: effect of immobilized heparin. Ann Thorac Surg 1994;58:421-4.

5. Kirklin JK, Westaby S, Blackstone EH, Kirklin JW, Chenoweth DE, Pacifico AD. Complement and the damaging effects of cardiopulmonary bypass. J Thorac Cardiovasc Surg 1983;86:845-57.

6. Redmond JM, Gillinov AM, Stuart RS, Zehr KS, Winkelstein JA, Herskowitz A, et al. Heparin-coated bypass circuits reduce pulmonary injury. Ann Thorac Surg 1993;56:474-9.

7. Von Segesser LK, Weiss BM, Pasic M, Garcia E, Turina MI. Risk and benefit of low systemic heparinization during open heart operations. Ann Thorac Surg 1994;58:391-8.

8. Aldea GS, Doursounian BA, O'Gara P, Treanor P, Shapira OM, Lazar HL, et al. Heparin-bonded circuits with a reduced anticoagulation protocol in primary CABG: a prospective, randomized study. Ann Thorac Surg 1996;62:410-8.

9. Øvrum E, Åm Holen E, Tangen G, Brosstad F, Abdelnoor M, Ringdal MAL, et al. Completely heparinized cardiopulmonary bypass and reduced systemic heparin; clinical and hemostatic effects. Ann Thorac Surg 1995;60:365-71.

10. Svenmarker S, Sandstrom E, Karlsson T, Jansson E, Haggmark S, Lindholm R, et al. Clinical effects of the heparin coated surface in cardiopulmonary bypass. Eur J Cardiothorac Surg 1997;11:957-64.
11. Wendel HP, Ziemer G. Coating-techniques to improve the hemocompatibility of artificial devices used for extracorporeal circulation. Eur J Cardiothorac Surg 1999;16:342-50.

12. Larm O, Larsson R, Olsson P. A new non-thrombogenic surface prepared by selective covalent binding of heparin via a modified reducing terminal residue. Biomat Med Dev Art Org 1983;11: 161-73.

13. Hsu LC. Principles of heparin-coating techniques. Perfusion 1991;6:209-19.

14. Øvrum E, Mollnes TE, Fosse E, Åm Holen E, Tangen G, Abdelnoor M, et al. Complement and granulocyte activation in two different types of heparinized extracorporeal circuits. J Thorac Cardiovasc Surg 1995; 110:1623-32.

15. Moen O, Fosse E, Brockmeier V, Andersson C, Mollnes TE, Høgasen K, et al. Disparity in blood activation by two different heparin-coated cardiopulmonary bypass systems. Ann Thorac Surg 1995;60:1317-23.

16. Lundblad R, Moen O, Fosse E. Endothelin-1 and neutrophil activation during heparin-coated cardiopulmonary bypass. Ann Thorac Surg 1997;63:1361-7.

17. Øvrum E, Åm Holen E, Tangen G. Consistent non-pharmacologic blood conservation in primary and reoperative coronary artery bypass grafting. Eur J Cardiothorac Surg 1995;9:30-5.

18. Flom-Halvorsen HI, Øvrum E, Abdelnoor M, Bjørnsen S, Brosstad F. Assessment of heparin anticoagulation: comparison of two commercially available methods. Ann Thorac Surg 1999;67:1012-6.

19. Aldea G, O’Gara P, Shapira OM, Treanor P, Osman A, Palatis E, et al. Effect of anticoagulation protocol on outcome in patients undergoing $\mathrm{CABG}$ with heparin-bonded cardiopulmonary bypass circuits. Ann Thorac Surg 1998;65:425-33.

20. Khuri SF, Valeri CR, Loscalzo J, Weinstein MJ, Birjinik V, Healey NA, et al. Heparin causes platelet dysfunction and induces fibrinolysis before cardiopulmonary bypass. Ann Thorac Surg 1995;60:1008-14.

21. Øvrum E, Brosstad F, Åm Holen E, Tangen G, Abdelnoor M. Effects on coagulation and fibrinolysis with reduced versus full systemic heparinization and heparin-coated cardiopulmonary bypass. Circulation 1995;92:2579-84.

22. Shapira N, Schaff HV, Piehler JM, White RD, Sill JC, Pluth JR. Cardiovascular effects of protamine sulfate in man. J Thorac Cardiovasc Surg 1982;84:505-14.

23. Wildevuur CRH, Jansen PGM, Bezemer PD, Kuik DJ, Eijsman L, Bruins P, et al. Clinical evaluation of Duraflo II heparin treated extracorporeal circulation circuits (2nd version). The European working group on heparin coated extracorporeal circulation circuits. Eur J Cardiothorac Surg 1997;11:616-23.

24. Ranucci M, Mazzucco A, Pessotto R, Grillone G, Casati V, Porreca L, et al. Heparin-coated circuits for high-risk patients: a multicenter, prospective, randomized trial. Ann Thorac Surg 1999;67:994-1000.

25. Øvrum E, Åm Holen E, Tangen G, Ringdal MAL. Heparinized cardiopulmonary bypass and full heparin dose marginally improve clinical performance. Ann Thorac Surg 1996;62:112833. 